\title{
DISPLAY LED MEKANIS BERBASIS MIKROKONTROLER
}

\author{
Andi Fitriati ${ }^{*}$, Muhammad Akil', Arham Anwar ${ }^{3}$ \\ 1,2,3 Jurusan Teknik Mekatronika Politeknik Bosowa \\ *e-mail: andi.fitriati@bosowa.co.id
}

\begin{abstract}
Generally, a display LED which can display character in large numbers and needs many LEDs too. The aim of this research is to make display LED using 16 LEDs which arranged in horizontal. That display LED is well known in mechanical display LED or propeller LED that can display many characters. The work of mechanical display LED rotates lines of LEDs in high speed and utilizes the speed of LEDs blink alternately, so in the certain speed can form a character letter or number. The method used in this research is a quasiexperimental methods. Basically, this tool utilizes optical phenomenon commonly called Persistence of Vision. Persistence of Vision is the inability of the human eye to see a rapid change of image, so they translate as image sequence. Mechanical LED display is equipped with Infrared remote to give input in real time on the display. Sensor Hall-Effect in Mechanical LED display is used as position of display reference when the display rotates. Input is processed by microcontroller Atmegal6A to control LED. The data which received by microcontroller was displayed in 16 LEDs that rotated by DC motor on 2400 rpm speed. Based on the result and observation of the project, the mechanical LED display can display clock using RTC IC. The communication with infrared remote can send well the data at maximum distance of 5 meters without obstructions.
\end{abstract}

Keywords : Display LED, Microcontroller, Infrared, RTC

\begin{abstract}
Abstrak
Pada umumnya, suatu LED display yang dapat menampilkan karakter dalam jumlah yang banyak membutuhkan jumlah LED yang banyak pula. Penelitian ini bertujuan untuk membuat suatu LED display yang hanya menggunakan 16 buah LED yang disusun horizontal disebut Display LED Mekanis atau Propeller Display yang mampu menampilkan berbagai karakter. Display LED Mekanis bekerja dengan cara memutar barisan LED dengan kecepatan tinggi dan memanfaatkan kedipan LED yang cepat dan bergantian, sehingga pada kecepatan tertentu dapat membentuk suatu karakter huruf, atau angka. Metode yang digunakan pada penelitian ini adalah Metode Kuasi Eksperimental. Pada dasarnya alat ini memanfaatkan fenomena optik yang biasa disebut Persistence of Vision. Persistence of Vision merupakan ketidakmampuan mata manusia untuk melihat pergantian gambar yang cepat, sehingga menerjemahkannya sebagai gambar yang berurutan. Display LED Mekanis dilengapi dengan remote infrared untuk memberi input secara real time pada tampilan display. Sensor Hall-Effect pada Display LED Mekanis digunakan sebagai posisi referensi tampilan ketika display berputar. Input diolah menggunakan Mikrokontroler Atmega16A untuk mengontrol LED. Data yang diterima kemudian ditampilkan pada 16 LED yang diputar oleh sebuah motor DC berkecepatan $2400 \mathrm{rpm}$. Dari hasil realisasi dan pengamatan data, display LED mekanis dapat berfungsi dengan menampilkan jam analog dan digital dan juga karakter yang memanfaatkan IC RTC. Komunikasi dengan remote infrared mampu mengirimkan data dengan baik pada jarak maksimum 5 meter tanpa penghalang.
\end{abstract}

Kata kunci : Display LED, Mikrokontroler, Infrared, RTC 


\section{Pendahuluan}

Display LED Mekanis adalah media penampil dengan memanfaatkan barisan LED yang berputar. LED yang berputar ini akan menimbulkan ilusi berupa angka diudara. Peristiwa ini berhubungan erat dengan fenomena optik yang biasa disebut Persistence of Vision, yaitu ketidak mampuan mata manusia melihat pergantian gambar yang cepat sekitar 1/25 detik [1].

Dengan ide dasar yang dijelaskan sebelumnya, maka 16 buah LED diputar dan barisan LED tersebut diaktifkan pada interval waktu yang tepat, sehingga menampilkan pola tampilan tertentu seperti karakter huruf maupun angka. Jika interval waktu yang dijelaskan sebelumnya merepresentasikan 360 kolom LED. Maka dengan Display LED Mekanis , 16 buah LED dapat melakukan tugas dari 5760 buah LED.

Secara umum, alat ini dapat digunakan untuk menampilkan jam. Dalam penelitian ini akan dicoba untuk menanamkan fitur RTC (Real Time Clock) sehingga waktu akan tersimpan meskipun kondisi alat dalam keadaan nonaktif. Agar jam dapat dikonfigurasi, maka digunakan interface Infrared yang bersifat nirkabel.

\section{Display LED Mekanis}

Komponen utama pada Display LED Mekanis adalah mikrokontroler ATmega16A dan LED. Sedangkan Sensor Hall-effect dan Sensor Infrared digunakan sebagai media input.

Sensor Hall-effect berfungsi sebagai pendeteksi posisi Display LED. Jika terjadi input pada Sensor Hall-effect maka mikrokontroler menganggap posisi Display pada posisi 0 derajat. Dari posisi inilah mikrokontroler mulai mengontrol pola LED hingga mencapai posisi 360 derajat. Adapun waktu yang ditampilkan disesuaikan dengan IC RTC yang memiliki kemampuan menyimpan waktu secara real-time.

Untuk melakukan konfigurasi waktu pada Display LED Mekanis maka digunakan interface Infrared, setelah waktu dikonfigurasi menggunakan remote infrared maka mikrokontroler akan mengirimkan data waktu yang baru ke IC RTC.

Untuk pola tampilan karakter dapat digunakan representasi dot-matriks $5 \times 8$. Sebagai contoh, untuk menampilkan karakter huruf 'A' dengan resolusi $5 * 7$ maka data yang ditampilkan sesuai dengan gambar 1.

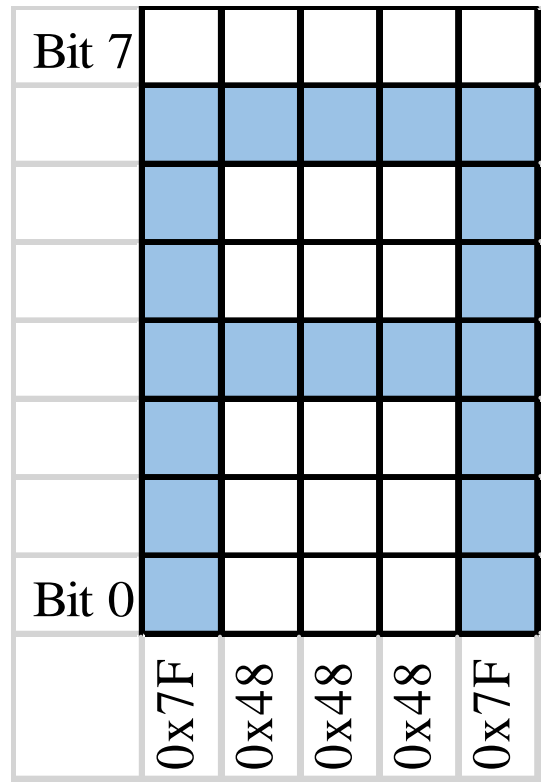

Gambar 1. Data Karakter A dengan Resolusi 5x7

Pada gambar 1 data setiap kolom merupakan data yang nantinya digunakan mikrokontroler untuk mengontrol pola LED pada Display LED Mekanis setiap derajatnya yang akan menampilkan karakter huruf ' $A$ ' [2].

\section{Metoda Penelitian}

Metode penelitian yang digunakan dalam penelitian ini adalah metode kuasi eksperimental yang mana peneliti tidak dapat mengatur sekehendak hati variabel bebasnya. Perancangan dan pembuatan prototype menggunakan sistem trial dan error. Pencarian literature pustaka merupakan langkah awal dari penelitian ini.

Penelitian ini diawali dengan tinjauan pustaka serta pengumpulan datadata penelitian sebelumnya, yang 
kemudian selanjutnya dilakukan ujicoba secara langsung.

\section{Perancangan}

Gambar 2 berikut ini menunjukkan diagram blok sistem yang dimulai dengan Sumber daya DC 12 volt di regulasi menjadi 9 volt. Motor DC bekerja dengan disuplai tegangan sebesar 9 volt. Untuk Display LED yang berputar, tegangan disuplai melalui udara. Prinsip ini memanfaatkan medan induksi pada coil. Karena tegangan yang diterima pada coil penerima berupa sinyal AC maka dibutuhkan penyearah Full-wave untuk menghasilkan sinyal DC.

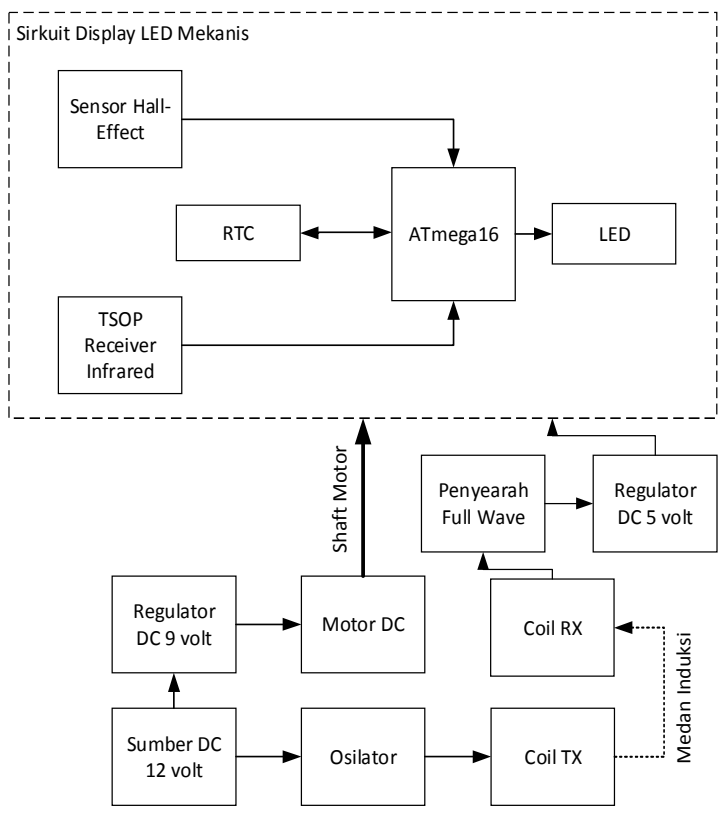

Gambar 2. Blok Diagram Sistem

Sinyal DC tersebut kemudian diregulasi kembali menajdi 5 volt untuk suplai tegangan Display LED [3].

ATmega16A berfungsi untuk mengeksekusi program dan mengirimkan sinyal perintah ke LED. Sensor hall-effect berfungsi sebagai pendeteksi posisi referensi, yang menandakan bahwa display LED telah melakukan satu rotasi penuh. Sensor Infrared berfungsi menerima sinyal perintah yang akan mengatur tampilan jam dari display LED.

Ketika motor berputar dan display led aktif maka mikrokontroler akan melakukan pengecekan awal pada IC RTC untuk mengambil waktu setelah itu menunggu sinyal dari sensor hall-effect.

Sinyal yang terdeteksi akan memanggil fungsi untuk mengontrol pola LED setiap derajat, selama derajat tidak melebihi 360 . Jika derajat sama dengan 360 atau lebih maka mikrokontroler akan menghentikan pengontrolan pola LED dan menunggu sinyal selanjutnya dari sensor hall-effect (lihat gambar 3).

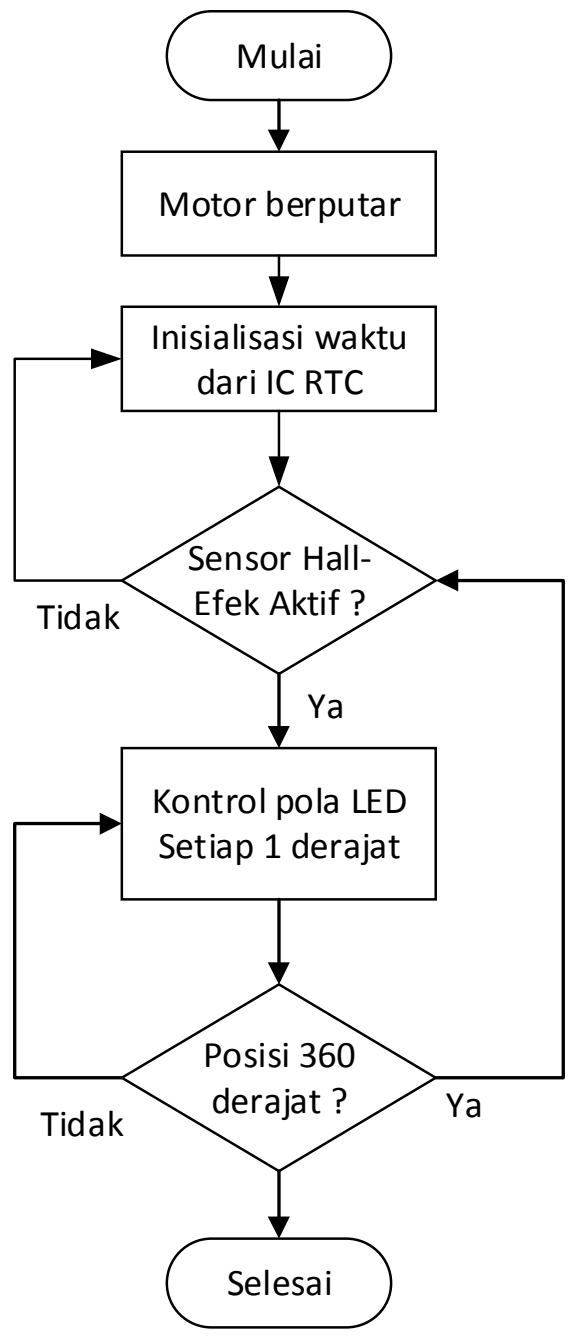

Gambar 3. Flow Chart Sistem 


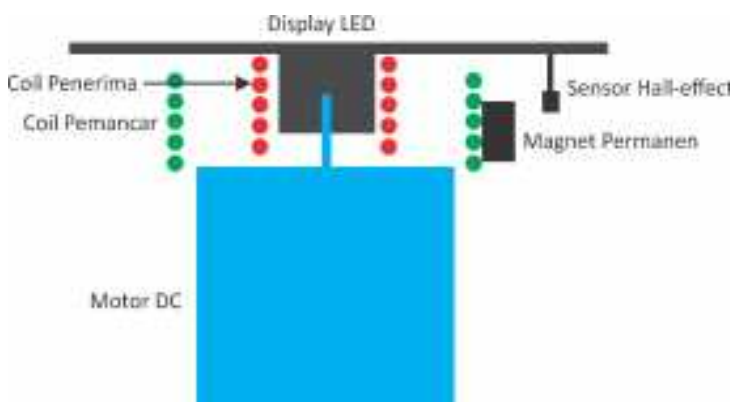

Gambar 4. Desain Mekanik

Pada gambar 4, display LED melekat pada as motor DC dengan menggunakan piringan pemutar DVD. Coil penerima medan induksi melekat pada bagian Display LED. Sedangkan Coil pemancar medan induksi melekat pada bagian Motor DC. Diameter coil penerima lebih kecil daripada coil pemancar medan induksi. Magnet permanen dipasang pada posisi tertentu yang akan dideteksi oleh sensor hall-effect [4]

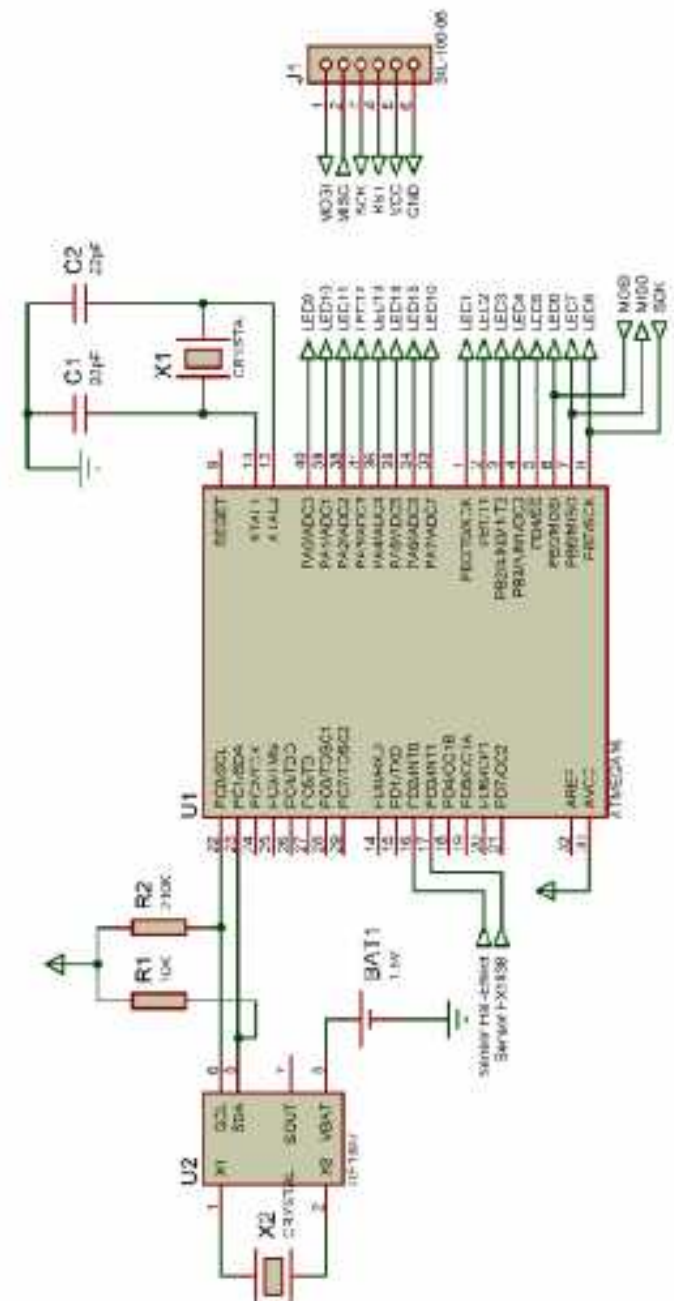

Gambar 5. Skematik Rangkaian
Sistem yang dirancang menggunakan 16 Buah LED, sehingga kebutuhan Port pada Atmega16A mencukupi. Kristal Eksternal memiliki nilai $16 \mathrm{MHz}$, nilai ini merupakan nilai maksimum yang didukung oleh ATmega16A. PortA mengontrol 8 Led bagian luar sedangkan, PORTB mengontrol 8 Led bagian dalam.

IC DS1037 memiliki Kristal $32.768 \mathrm{KHz}$ agar beroperasi dengan normal, baterai jenis CR2032 digunakan sebagai sumber cadangan ketika display dalam keadaan nonaktif. IC DS1037 berhubungan dengan ATmega16A melalui interface TWI (Two Wire Interface), yang hanya menggunakan dua jalur penghantar.

Pada perancangan software, terdapat beberapa rutin, yakni routing komunikasi TWI, routing infrared decoder, dan routing timer.

IC DS1307 bekerja dengan memanfaatkan komunikasi TWI. Pada umumnya ada dua kecepatan data yang didukung oleh komunikasi ini yaitu 100 $\mathrm{KHz}$ dan $400 \mathrm{KHz}$, namun DS1307 hanya mendukung kecepatan $100 \mathrm{KHz}$. Maka dari itu TWI pada Atmega dikonfigurasi pada kecepatan $100 \mathrm{KHz}$. [5]

Pada komunikasi TWI, dikenal istilah Master dan Slave. Master adalah perangkat yang berfungsi untuk mengontrol jalur data. Sedangkan Slave hanya berfungsi sebagai pembaca perintah pada jalur data. Karena mampu mendukung hingga 128 perangkat, maka setiap perangkat harus memiliki Alamatnya sendiri. DS1307 memiliki alamat 110100X (X merupakan bit penanda bahwa dilakukan proses membaca atau menulis).

Rutin infrared decoder pada system ini berfungsi untuk menerjemahkan sinyal data serial dari remote menjadi sinyal perintah, yang akan diproses oleh mikrokontroler untuk mengambil tindakan atau langkah selanjutnya. [6]

Dalam satu rotasi penuh $\left(360^{\circ}\right)$ akan dicari waktu yang dibutuhkan motor dalam 
melakukan putaran sebesar $1^{\circ}$. Maka digunakan fitur timer pada mikrokontroler.

\section{Hasil}

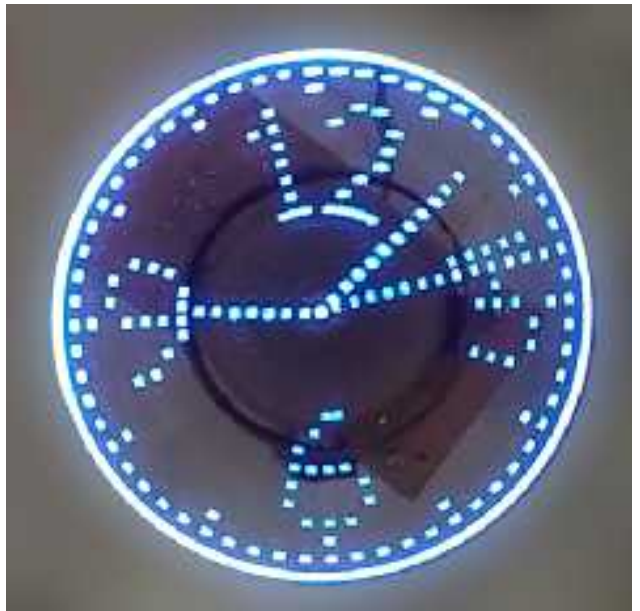

Gambar 6. Display dalam Mode Jam Analog

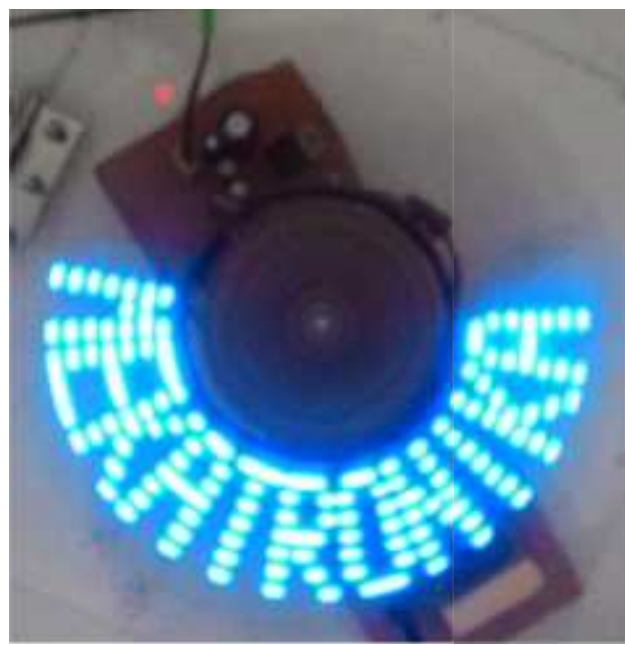

Gambar 7. Display dalam Mode Teks

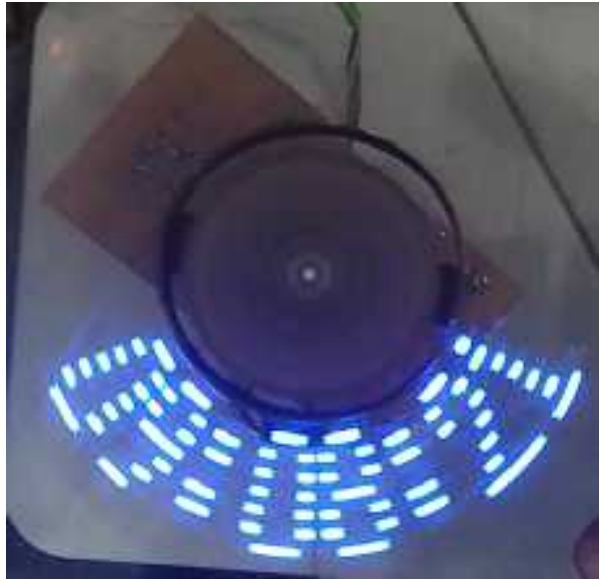

Gambar 8. Display dalam Mode Jam Digital

Ketika tombol pada remote ditekan maka tampilan pada Display LED Mekanis akan terganggu. Hal ini disebabkan oleh proses decoding infrared sekitar $67.5 \mathrm{~ms}$ yaitu panjang tetap yang dimiliki satu data penuh.

Secara matematis hal ini dapat dibuktikan melalui hitungan delay per derajat dengan satu data perintah dari remote infrared.

Putaran motor $=2400 \mathrm{rpm}$

Putaran motor dalam rps :

$$
\frac{2400}{60}=40
$$

Waktu yang dibutuhkan untuk satu putaran penuh :

$$
\frac{1}{40}=0.025
$$

Jadi, jumlah putaran yang dipengaruhi oleh decoding infrared adalah :

$$
\begin{aligned}
& \frac{0.0675 \text { detik }}{0.025}=2.7 \\
& \frac{0.0675 \text { detik }}{0.025} \approx 3
\end{aligned}
$$

\section{Kesimpulan}

Berdasarkan pembahasan dan pengujian Display LED mekanis dapat ditarik kesimpulan bahwa :

1. Display LED mampu menampilkan jam baik dalam bentuk analog maupun digital dengan pengontrolan infrared meskipun terdapat gangguan pada tampilan LED, yang disebabkan oleh proses decoding sinyal infrared yang terlalu lama yakni $67,5 \mathrm{~ms}$.

2. Fitur RTC sudah dapat diterapkan pada display LED mekanis.

3. Display LED Mekanis setara dengan Display LED Konvensional yang menggunakan 16 × $360=5760$ LED

\section{Saran}

Diperlukan adanya penelitian lebih lanjut untuk kestabilan sumber tegangan dari sistem. 


\section{Daftar Pustaka}

[1]Coltheart M. The persistence of vision. Philos Trans R SocLond B Biol Sci. 1980 Jul 8; 290(1038):57-69. PMID 6106242

[2] Putra, Yudha A. 2011. Dot Matrix Display with Short Message Service based on Microcontroller ATMegal6. Surakarta : Final Project, Universitas Muhammadiyah Surakarta accessed on Juny $15^{\text {th }}, 2014$

[3]Rafik Manihar, Sheikh. 2012.The Power Saving Low Cost Rotating 8 Led Information Display. Ijser 3:1-5

[4]Malvino, Albert Paul. 1989. Prinsipprinsip Elektronika. Jakarta : Erlangga.

[5]J.B. Gupta, Electronic circuits and devices, 1sted, S.K Kataria and Sons, 2005

[6] Muhammed Ali Mazidi, Janice Gillispie Mazidi and Rolin D Mckinlay, The AVR Microcontroller and Embedded System Using Assembly and C, $2^{\text {nd }}$, Pearson, 2007 